\title{
Incidences of Fatalities on Austrian Ski Slopes: A 10-Year Analysis
}

\author{
Markus Posch ${ }^{1, *(\mathbb{C}}$, Alois Schranz ${ }^{2}$, Manfred Lener ${ }^{2}$, Martin Burtscher ${ }^{1}\left(\mathbb{D}\right.$ and Gerhard Rued1 ${ }^{1}(\mathbb{D})$ \\ 1 Department of Sport Science, University of Innsbruck, A-6020 Innsbruck, Austria \\ 2 Medalp Sportclinic, A-6460 Imst, Austria \\ * Correspondence: markus.posch@uibk.ac.at; Tel.: +43-512-507-45855
}

Received: 3 April 2020; Accepted: 21 April 2020; Published: 23 April 2020

\begin{abstract}
The study evaluated incidences and potential differences of traumatic and nontraumatic fatalities among recreational skiers and snowboarders on Austrian ski slopes within a 10-year analysis. Within this retrospective study, data were collected by the Federal Ministry of the Interior. Data comprised all traumatic and nontraumatic deaths on Austrian ski slopes which occurred between the 2008/09 and 2017/18 winter seasons. Age, sex, nationality, gear used, altitude, slope difficulty, accident cause, primary cause of death and helmet use were collected at the death scene. Incidence of fatalities was calculated based on number of skier days. In total, 369 fatalities, with an average of $36.9 \pm 7.9$ fatalities per year, were registered. The yearly incidence of traumatic and nontraumatic deaths decreased by $25.8 \%$ and $40.1 \%$ during the 10 -year time period, leading to an evaluated mean incidence of 0.70 deaths per million skier days, with an incidence of 0.36 traumatic deaths and 0.34 nontraumatic deaths per million skier days. Incidences of both traumatic and nontraumatic deaths decreased during the 10-year analysis, representing death as a rare event on Austrian ski slopes. However, adequate prevention measures to reduce potential risk factors to further reduce the mortality risk on ski slopes are needed.
\end{abstract}

Keywords: ski fatalities; Austrian ski slopes; traumatic; nontraumatic

\section{Introduction}

As more than 8 million skiers and snowboarders visit the Austrian Alps annually [1], recreational winter sport activities are associated with a certain risk of injury or death.

The overall incidence of ski injuries has decreased from 5-8 injuries per 1000 skier days [2] to 2-3 injuries per 1000 skier days in the 1990s [3,4] and the present evaluated injury rate in Austria is less than one injury per 1000 skier days [5]. In addition to non-fatal skiing-related injuries, ski fatalities also occur on ski slopes and a distinction is made between traumatic (e.g., collision with an object/person) and nontraumatic deaths (e.g., cardiac death) [6].

Regarding traumatic and nontraumatic fatal injuries on ski slopes, a rising trend of deaths rates could be shown between the period 1980 and 2001 by Xiang and Stallones [7] and death rates ranged from 0.53 to 1.88 deaths per million skier days. Later, after the turn of the millennium, the number of traumatic deaths among skiers has remained relatively stable, with incidences ranging from 0.37 [6] to 0.70 [8] and 0.75 deaths per million skier days [9]. Due to the lack of published literature/studies, the development of nontraumatic death incidences in the last two decades cannot be described properly.

In Austria, a study [6], evaluating incidences of fatalities between the years 2005 and 2010 revealed that the overall incidence of fatalities is 0.79 deaths per million skier days with an incidence of 0.42 nontraumatic deaths and 0.37 traumatic deaths per million skier days. Nowadays, the present evaluated injury rate in recreational alpine skiing in Austria is 0.6 injuries per 1000 skier days [5]. Therefore, ski fatalities on ski slopes are generally rare events compared to non-fatal skiing-related 
injuries [9]. When comparing fatal events on ski slopes with other mountain sport activities, the death risk during mountain hiking in the Alps is about five times, and during ice and rock climbing in the Alps or trekking in Nepal, about 10 times, higher than during alpine skiing [10].

Although a study by Ruedl et al. [6] reported of an average of 41 fatalities per year, the literature about ski fatalities and causes of fatalities among recreational skiers and snowboarders on Austrian ski slopes is scarce [6], especially long-term data on traumatic and nontraumatic fatalities for Austria.

Burtscher and Ponchia [11] reported that the risk of severe cardiovascular adverse events, accounting for most nontraumatic deaths [12,13], increases sharply in men over the age of 35 suffering from coronary artery disease, particularly those with prior myocardial infarction, and/or risk factors like arterial hypertension, hypercholesterolemia, or diabetes. To the best of our knowledge, no study investigated the potential risk factors regarding both traumatic and nontraumatic deaths on ski slopes. Furthermore, the majority of the available literature does not include data on nontraumatic deaths on ski slopes $[8,9,14]$.

Thus, the goal of this study was to evaluate current incidences and potential differences of traumatic and nontraumatic fatalities among recreational skiers and snowboarders on Austrian ski slopes within a 10-year period from the winter seasons 2008/09 to 2017/18.

\section{Materials and Methods}

In this retrospective study data were collected by members of the Federal Ministry of the Interior (FMI), who are qualified alpinists and have paramedical training. Data comprised all fatalities, including traumatic and nontraumatic deaths on Austrian ski slopes which occurred between the 2008/09 and 2017/18 winter seasons. Age, sex (male, female), nationality (Austrian, German, others), gear used (ski, snowboard, others), altitude, slope difficulty (easy, moderate, hard, unknown), accident cause (fall, collision, avalanche, sudden cardiac death, others), primary cause of death and helmet use (yes, no) were collected at the death scene and stored by the FMI and the Austrian Kuratorium für Alpine Sicherheit (KFAS). Causes of death were always determined by emergency physicians on the accident scene using information from companions and eyewitnesses. Incidence of fatalities was calculated based on the number of skier days during this 10-year period, which was offered by the Federation of Austrian ski lift companies.

This study was performed in conformity with the ethical standards of the 2008 Declaration of Helsinki. Furthermore, this study was approved (approval ID-62/2019) by the institutional review board (IRB) of the Department of Sport Science as well as the Board for Ethical Issues (BfEI) of the University of Innsbruck.

\section{Statistics}

Data are presented as means and standard deviations, as well as absolute and relative frequencies. Factors with more than two categories (slope difficulty) were binary coded by making dummy variables for every single category to achieve univariate odds ratio (OR). Adjusted ORs and their $95 \%$ CIs for nontraumatic death are reported. To evaluate the changes of incidences of traumatic and nontraumatic deaths (winter seasons 2008/09-2017/18), the percentage of changes were calculated. According to the tests of normal distribution (Kolmogorov Smirnov) differences between traumatic and nontraumatic deaths in age and altitude were evaluated either by independent $t$-tests or Mann-Whitney-U tests. Differences between traumatic and nontraumatic deaths in frequencies (sex, gear used, slope difficulty) were computed by chi-square tests. SPSS 24.0 (IBM Corporation, Armonk, NY, USA) was used for the statistical analysis. All $p$-values were two-tailed and values of $p<0.05$ were considered to indicate statistical significance.

\section{Results}

In total, 369 fatalities during the time period between the winter seasons 2008/09 and 2017/18, with an average of $36.9 \pm 7.9$ fatalities per year, were registered (Figure 1). 


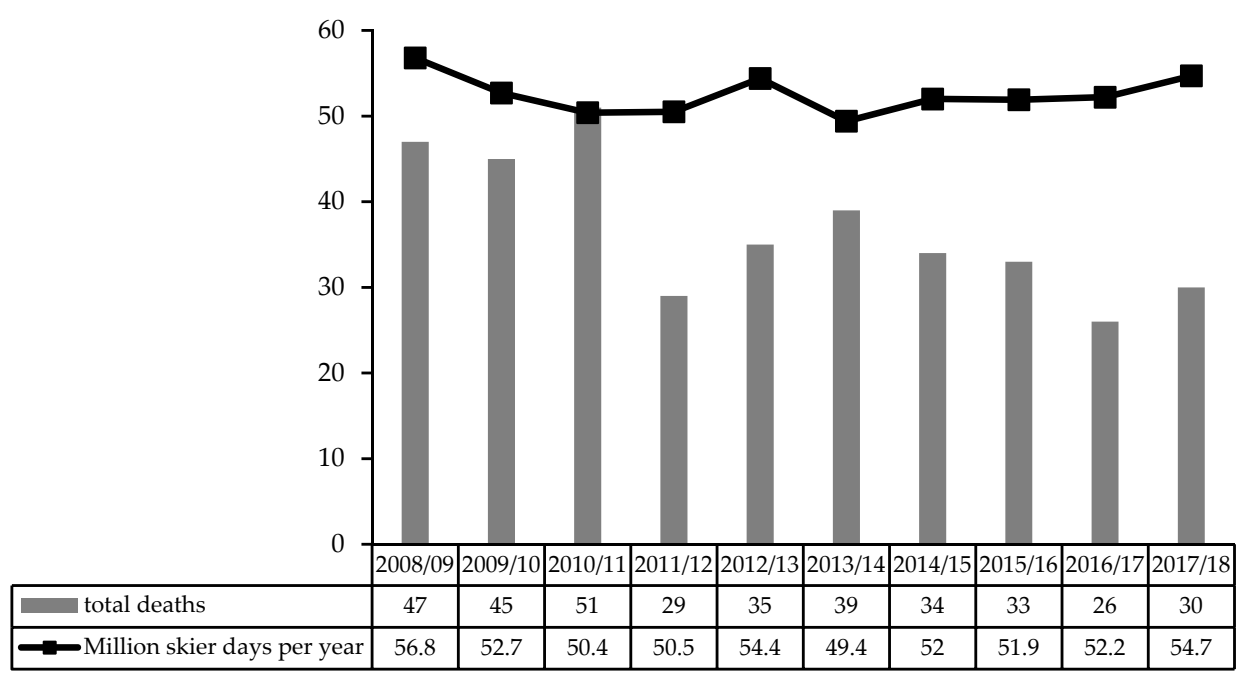

Figure 1. Number of total deaths and million skier days per year from winter season 2008/09 to 2017/18.

Most of fatalities occurred in males (87.3\%) and in skiers (95.5\%). Mean age was $51.0 \pm 18.3$ years and average altitude at time of death was $1552.0 \pm 674.1 \mathrm{~m}$ above sea level. The majority of victims were citizens of Germany (40.7\%) followed by Austrians (31.7\%) and people from other countries $(27.6 \%)$.

The evaluated mean incidence during this 10-year period (2008/09-2017/18) was 0.70 deaths per million skier days, with an incidence of 0.36 traumatic deaths and 0.34 nontraumatic deaths per million skier days (Figure 2).

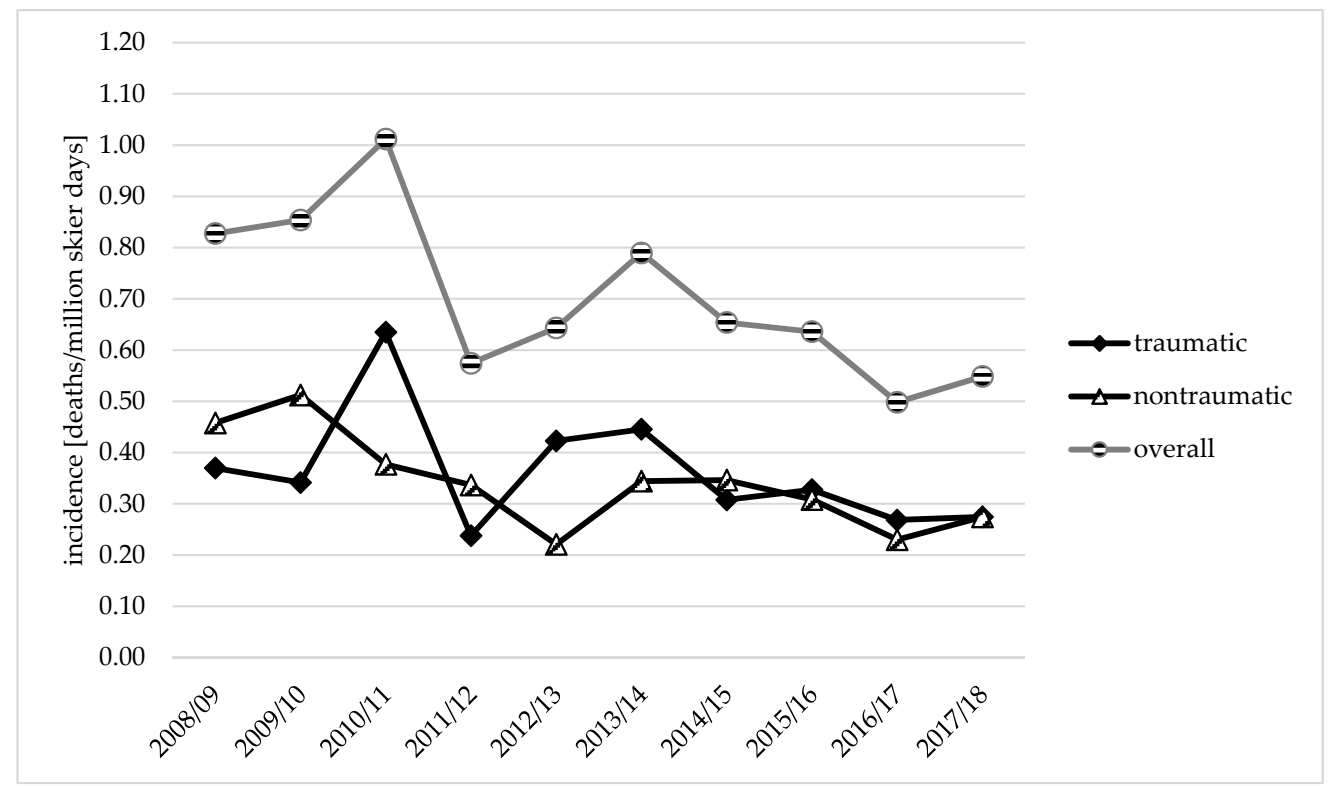

Figure 2. Changes in incidences of traumatic and nontraumatic deaths on Austrian ski slopes in recreational alpine skiers and snowboarders within a 10-year analysis.

From the winter season 2008/09 to 2017/18, the yearly incidence of traumatic deaths decreased $(-25.8 \%)$ from $0.37(2008 / 09)$ to 0.27 deaths per million skier days, while the incidence of nontraumatic deaths decreased $(-40.1 \%)$ from 0.46 to 0.27 deaths per million skier days. The highest incidences were reported in the winter season 2010/11 for traumatic ( 0.63 deaths per million skier days) and in 2009/10 for nontraumatic deaths ( 0.51 deaths per million skier days). The lowest incidences of 0.24 traumatic deaths were reported in 2011/12, whereas incidences of 0.22 nontraumatic deaths per million skier days were lowest in 2012/13. The course of traumatic death incidence was similar to that of the overall 
death incidence, whereas a different trend was shown among nontraumatic death incidence, especially between the period from 2008/09 to 2012/13 compared to overall death incidence (Figure 2).

In sum, $190(51.5 \%)$ were traumatic deaths and 179 (48.5\%) were nontraumatic deaths. The causes of traumatic and nontraumatic deaths are presented in Table 1 . More than $50 \%$ of traumatic deaths were due to collisions with other skiers and objects like trees and rocks, as well as man-made objects such as pylons, fences and a snow groomer. Regarding traumatic deaths, fatal head injuries were the primary cause of death and occurred in 103 victims (54.2\%), of whom $63(61.2 \%)$ wore a helmet. A sudden cardiac death (SCD) caused the majority (99.4\%) of nontraumatic deaths.

Table 1. Causes of traumatic $(n=190)$ and nontraumatic deaths $(n=179)$ on Austrian ski slopes between winter seasons 2008/09 and 2017/18.

\begin{tabular}{cccc}
\hline Causes of Traumatic Deaths & {$[n, \%]$} & Causes of Nontraumatic Deaths & {$[n, \%]$} \\
\hline Fall during skiing & $89(46.8)$ & Sudden cardiac death during skiing & $138(77.0)$ \\
\hline Collision with object & $76(40.0)$ & Sudden cardiac death while standing on the slope & $24(13.4)$ \\
\hline Collision with a skier & $23(12.2)$ & Sudden cardiac death on the lift & $15(8.4)$ \\
\hline Avalanche on slope & $2(1.0)$ & Sudden cardiac death in ski huts & $1(0.6)$ \\
\hline & & unknown & $1(0.6)$ \\
\hline
\end{tabular}

Data are presented as absolute and relative frequencies.

In Table 2, the characteristics of factors associated with traumatic and nontraumatic deaths among fatally injured skiers and snowboarders were shown. Nontraumatic deaths were significantly $(p=0.001)$ higher for males compared to females (93.3\% vs. 6.7\%). Furthermore, a higher age was significantly associated with nontraumatic death $(p<0.001)$, whereas reported altitude at time of death, used gear and slope difficulty was not significantly different between traumatic and nontraumatic cases $(p>0.05)$.

Table 2. Characteristics of factors associated with traumatic and nontraumatic deaths among recreational skiers and snowboarders on Austrian ski slopes between winter seasons 2008/09 and 2017/18.

\begin{tabular}{|c|c|c|c|c|}
\hline & $\begin{array}{l}\text { Traumatic Deaths } \\
\qquad(n=190)\end{array}$ & $\begin{array}{c}\text { Nontraumatic } \\
\text { Deaths }(n=179)\end{array}$ & $p$-Value & $\begin{array}{l}\text { Univariate Odds } \\
\text { Ratio }(95 \% \text { CI) }\end{array}$ \\
\hline \multicolumn{5}{|l|}{$\operatorname{Sex}[n, \%]$} \\
\hline Male & 155 (81.6) & $167(93.3)$ & 0.001 & $3.14(1.57-6.27)$ \\
\hline Female & $35(18.4)$ & $12(6.7)$ & & \\
\hline Age [years] & $42.8 \pm 19.0$ & $59.8 \pm 12.7$ & $<0.001$ & 1.07 (1.05-1.09) \\
\hline Altitude [m] & $1509.3 \pm 640.5$ & $1597.3 \pm 707.0$ & 0.106 & $1.03(1.01-1.05)$ \\
\hline \multicolumn{5}{|l|}{ Gear used $[n, \%]$} \\
\hline Ski & 177 (93.1) & $176(98.3)$ & & \\
\hline Snowboard & $13(6.9)$ & $3(1.7)$ & 0.087 & $0.45(0.18-1.12)$ \\
\hline \multicolumn{5}{|l|}{ Slope difficulty } \\
\hline easy (blue) & 67 (35.3) & 75 (41.9) & 0.455 & $1.18(0.76-1.84)$ \\
\hline moderate (red) & $95(50.0)$ & $72(40.2)$ & 0.136 & $0.73(0.48-1.11)$ \\
\hline hard (black) & $16(8.4)$ & $10(5.6)$ & 0.352 & $0.68(0.30-1.54)$ \\
\hline unknown & $12(6.3)$ & $22(12.3)$ & & \\
\hline
\end{tabular}

Data are presented as mean values \pm standard deviation, absolute and relative frequencies and odds ratios $(95 \% \mathrm{CI})$.

\section{Discussion}

The aim of the present study was to evaluate incidences and causes of traumatic and nontraumatic deaths among recreational skiers and snowboarders on Austrian ski slopes within a 10-year period 
from winter seasons 2008/09 to 2017/18. Furthermore, potential differences between traumatic and nontraumatic death cases were investigated.

The mean incidence of fatalities between $2008 / 09$ and 2017/18 was $36.9 \pm 7.9$ deaths per year. In comparison, studies by Shealy et al. [9] and Ruedl et al. [6] reported $38.5 \pm 6.0$ and $41.1 \pm 6.4$ deaths on average per winter season. The overall incidence rate of 0.70 deaths per million skier days is lower than shown in studies by Ruedl et al. [6], Shealy et al. [9] and Bianchi et al. [8], reporting 0.79, 0.75 and 0.70 deaths per million skier days.

Over the 10-year study period, incidence of traumatic deaths decreased by more than $25 \%$, while the incidence of nontraumatic deaths has reduced by around $40 \%$.

With regard to Austria, the FMI and the KFAS, concerned with collecting and storing the data, differentiate between traumatic (fall, collision with skier/object, avalanche, etc.) and nontraumatic deaths (sudden cardiac death). Therefore, the present study included all deaths, both traumatic and nontraumatic, while Shealy et al. [9] and Bianchi et al. [8] only documented traumatic deaths. In the underlying study, the incidence of traumatic deaths was 0.36 per million skier days and was much lower compared to incidences reported by studies of Shealy et al. [9] and Bianchi et al. [8]. The abovementioned studies [8,9] analyzed deaths rates in the period from 1991/92 to 2012. Looking at the development of incidences of non-fatal ski injuries at the same time, studies showed a decrease from 5-8 injuries per 1000 skier days before the 1970s [2], to 2-3 injuries per 1000 skier days in the 1980s and early 1990s [3,4] due to advances in equipment and increased helmet use [15]. It might be possible that the incidence of traumatic fatal injuries has benefitted from this decline and from the mentioned equipment-related improvements to a certain extent. Regarding data about Austria, incidences of traumatic ( 0.36 ) and nontraumatic (0.34) deaths in the present study were lower compared to results of a previous study by Ruedl et al. [6], who reported an incidence of 0.37 traumatic deaths and 0.42 nontraumatic deaths per million skier days. A potential reason for the lower traumatic death incidences in the present study could be improved skiing ability, as individual skiing skills are related to the injury rate [16-18]. In their study, Ekeland et al. [16] reported that beginners had an injury rate three times that of expert skiers. Furthermore, Ekeland et al. [19] showed that skiing ability increased significantly during the selected 12-year from 2000 to 2012.

Looking at the course of overall death incidence, a similar trend was shown among traumatic death incidence. A possible reason could be that traumatic deaths represented the predominant type of death among recreational skiers and snowboarders. On the other hand, a different trend was shown among nontraumatic death incidence compared to the overall incidence. Nevertheless, both, traumatic and nontraumatic death incidence decreased over the 10-year time period, resulting in an incidence of 0.27 deaths per million skier days.

The majority of the available literature showed collisions with solid objects and other skiers to be the most common scenario of a traumatic death on ski slopes $[6,7,9]$. These results seem to be in line with results of the present study, where more than $50 \%$ of traumatic deaths were due to collisions with other skiers and solid and man-made objects. In contrast, a study conducted in Switzerland by Bianchi and Brügger [14] reported a fall during skiing to be the primary cause ( $47 \%)$ of traumatic deaths on ski slopes. Although improvements have been taking place in terms of slope preparation, safety standards on ski slopes and creating awareness of potential risk factors, numbers of skiers are likely to increase and fatal collisions are still happening. According to a study by Ruedl et al. [20], that investigated the causes and factors associated with collisions on ski slopes, preventive recommendations to reduce the risk of a collision include an adaptation of the individual skiing or snowboarding behaviour and the actual speed depending on skill level, weather conditions and the number of other skiers and snowboarders on ski slopes.

It is well known that SCD represents the leading cause for nontraumatic deaths at altitude performing leisure time activities such as recreational skiing [11-13]. Confirming these results, the underlying findings represent SCD as the major cause of nontraumatic deaths (99\%) on Austrian ski slopes in the last 10 years. Compared to results of a study by Ruedl et al. [6], who stated that SCD 
was the cause of nontraumatic death in more than $73 \%$ of cases, the results of the underlying study are even higher, proofing the existence and importance of this cardiovascular event.

Well in accordance with the study by Ruedl et al. [6], we found that mainly males $(87.3 \%)$, skiers $(95.5 \%)$ and persons older than 50 were involved in most deaths. This might be related to the fact that males show, in general, a higher risk-taking behaviour on ski slopes and are skiing faster compared to their female counterparts [1,21], leading to a potentially higher traumatic death rate. Moreover, males show a greater cardiovascular risk of suffering from SCD compared to females [6]. In the present study, the proportion of males was significantly greater in nontraumatic deaths than in traumatic deaths (OR 3.14, 95\% CI 1.57-6.27).

Several studies have also reported that males are more prone to fatalities on ski slopes $[7,9,12]$ and traumatic fatality risk is highest between $40-69$ years of age [14]. We found that more than $53 \%$ of all traumatic deaths were between 40 and 69 years old. With regard to SCD, which causes the majority of nontraumatic deaths, Burtscher and Ponchia [11] already reported an age $>34$ years as constituting the main risk group. In accordance with this, the results of the present study showed that more than $95 \%$ of nontraumatic deaths were older than 34 years. Furthermore, a higher age was significantly associated with nontraumatic death compared to traumatic death $(p<0.001)$. The vast majority of SCD in subjects older than 34 years of age is known mainly to be to due coronary artery disease [22], therefore an increasing frequency of SCDs with age is not surprising [12].

Furthermore, Burtscher [12] showed that SCD seems to be significantly more frequent at altitudes up to $2000 \mathrm{~m}$ compared to those over $2000 \mathrm{~m}$. However, further analysis did not detect altitude itself as an important risk factor regarding SCD [12]. Findings of the underlying study seem to be in line with results of Burtscher [12], as mean altitude at death scene was $1552.0 \pm 674.1 \mathrm{~m}$ above sea level. Moreover, underlying results revealed that altitude at death scene was not significantly different between traumatic and nontraumatic deaths. Burtscher [12] reported that the reason SCDs occurred most frequently at altitudes between 1500 and $2000 \mathrm{~m}$ may simply be due to the greater exposure times at that altitude.

Used gear (ski vs. snowboard) and slope difficulty were not significantly different between traumatic and nontraumatic deaths. Interestingly, most traumatic deaths (50\%) happened on moderate slopes, whereas the majority of nontraumatic deaths occurred on easy slopes $(42 \%)$.

The underlying findings suppose deaths on ski slopes are a rare event. Incidences of traumatic and nontraumatic deaths should not be underestimated, as recreational alpine skiing represent one of the most popular winter sports worldwide, with an estimated 400 million skier days annually [23]. However, raising awareness of potential risk factors and common dangers could help reduce fatalities on ski slopes. Based on the currently available evidence, it seems plausible that recreational alpine skiing, especially when performed on a regular basis, may contribute to healthy aging by its association with a healthier lifestyle, including higher levels of physical activity [24].

\section{Conclusions}

In conclusion, incidences of both traumatic and nontraumatic deaths decreased during the 10-year analysis. Nontraumatic deaths were significantly higher among males compared to females. Moreover, increasing age was significantly associated with nontraumatic death, and the majority of traumatic deaths were due to collisions with skiers and objects, whereas SCD caused most nontraumatic deaths. These findings highlight the need of adequate prevention measures to reduce potential risk factors and further decrease the mortality risk on ski slopes. 
Author Contributions: M.P. designed the study, conducted the data analysis and interpretation, and wrote the draft of the manuscript. A.S. contributed to designing the study, interpretation of the data and preparation of the manuscript. M.L. contributed to data collection and manuscript preparation. M.B. and G.R. contributed to data collection and handling, contributed to data analysis and preparation of the manuscript. All authors listed have made a substantial, direct and intellectual contribution to the work. All authors have read and agreed to the published version of the manuscript.

Funding: This research received no external funding.

Acknowledgments: The authors would like to deeply thank the Federation of Austrian ski lift companies for providing the number of skier days per year. Furthermore, the authors would like to thank Dagmar Walter and Regina Sterr of Österreichisches Kuratorium für Alpine Sicherheit for the provision of data.

Conflicts of Interest: The authors declare no conflict of interest.

\section{References}

1. Ruedl, G.; Sommersacher, R.; Woldrich, T.; Kopp, M.; Nachbauer, W.; Burtscher, M. Mean speed of winter sport participants depending on various factors. Sportverletz Sportschaden 2010, 24, 150-153. [CrossRef] [PubMed]

2. Johnson, R.J.; Pope, M.H.; Ettlinger, C.F. Ski injuries and equipment function. J. Sports Med. 1974, 2, $299-307$. [CrossRef] [PubMed]

3. Shealy, J.E. Comparison of Downhill Ski Injury Patterns 1978-81 vs. 1988-90. In Skiing Trauma and Safety; Johnson, R.J., Mote, C., Zelcer, J., Eds.; ASTM Intl: West Conshohocken, PA, USA, 1993; Volume 9, pp. 23 -32.

4. Warme, W.J.; Feagin, J.A.; King, P.; Lambert, K.L.; Cunningham, R.R. Ski Injury Statistics, 1982 to 1993, Jackson Hole Ski Resort. Am. J. Sports Med. 1995, 23, 597-600. [CrossRef] [PubMed]

5. Ruedl, G.; Philippe, M.; Sommersacher, R.; Dünnwald, T.; Kopp, M.; Burtscher, M. Current incidence of accidents on Austrian ski slopes. Sportverletz Sportschaden 2014, 28, 183-187. [PubMed]

6. Ruedl, G.; Bilek, H.; Ebner, H.; Gabl, K.; Kopp, M.; Burtscher, M. Fatalities on Austrian ski slopes during a 5-year period. Wild Environ. Med. 2011, 22, 326-328. [CrossRef] [PubMed]

7. Xiang, H.; Stallones, L. Deaths associated with snow skiing in Colorado 1980-81 to 2002-2001 ski seasons. Injury 2003, 34, 892-896. [CrossRef]

8. Bianchi, G.; Brügger, O.; Niemann, S. Skiing and snowboarding in Switzerland: Trends in injury and fatality rates over time. In Snow Sports Trauma and Safety; Scher, I.S., Greenwald, R.M., Petrone, N., Eds.; Springer: Berlin/Heidelberg, Germany, 2017; Volume 21, pp. 29-39.

9. Shealy, J.E.; Johnson, R.J.; Ettlinger, C.F. On piste fatalities in recreational snow sports in the U.S. In Skiing Trauma and Safety; Johnson, R.J., Shealy, J.E., Yamagishi, T., Eds.; ASTM Intl: West Conshohocken, PA, USA, 2006; Volume 16, pp. 1-8.

10. Burtscher, M. Climbing the Himalayas more safely. BMJ 2012, 344, e3778. [CrossRef] [PubMed]

11. Burtscher, M.; Ponchia, A. The risk of cardiovascular events during leisure time activities at altitude. Prog. Cardiovasc Dis. 2010, 52, 507-511. [CrossRef] [PubMed]

12. Burtscher, M. Risk of cardiovascular events during mountain activities. Adv. Exp. Med. Biol. 2007, 618, 1-11. [PubMed]

13. Burtscher, M. Downhill skiing: A putative model of hypoxia preconditioning. J. Clin. Exp. Cardiol. $2014,5$. [CrossRef]

14. Unfallgeschehen beim Ski- und Snowboardfahren in der Schweiz. 2015. Available online: https://www.bfu.ch/sites/assets/Shop/bfu_2.253.08_bfu\%20knowledge\%20base\%20\%E2\%80\%93\%

20Injuries\%20in\%20skiing\%20and\%20snowboarding\%20in\%20Switzerland.pdf (accessed on 28 October 2019).

15. Johnson, R.J.; Ettlinger, C.F.; Shealy, J.E. Myths concerning alpine skiing injuries. Sports Health 2009, 1, 486-492. [CrossRef] [PubMed]

16. Ekeland, A.; Sulheim, S.; Rødven, A. Injury rates and injury types in alpine skiing, telemarking and snowboarding. In Skiing Trauma and Safety; Johnson, R.J., Shealy, J.E., Ahlbäumer, M.G., Eds.; ASTM Intl: West Conshohocken, PA, USA, 2005; Volume 15, pp. 31-39.

17. Laporte, J.D.; Bajolle, L.; Lamy, D.; Delay, J.B. Winter sport injuries in France over two decades. In Skiing Trauma and Safety; Johnson, R.J., Shealy, J.E., Greenwald, R.M., Scher, I.S., Eds.; ASTM Intl: West Conshohocken, PA, USA, 2012; Volume 19, pp. 201-215. 
18. Shealy, J.E.; Ettlinger, C.F.; Scher, I.; Johnson, R.J. 2010/2011 NSAA 10-year interval injury study. In Skiing Trauma and Safety; Johnson, R.J., Shealy, J.E., Greenwald, R.M., Eds.; ASTM Intl: West Conshohocken, PA, USA, 2015; Volume 20, pp. 93-111.

19. Ekeland, A.; Rødven, A.; Heir, S. Injury trends in recreational skiers and boarders in the 16-year period 1996-2012. In Snow Sports Trauma and Safety; Scher, I.S., Greenwald, R.M., Petrone, N., Eds.; Springer: Berlin/Heidelberg, Germany, 2017; Volume 21, pp. 3-16.

20. Ruedl, G.; Kopp, M.; Sommersacher, R.; Woldrich, T.; Burtscher, M. Factors associated with injuries occurred on slope intersections and in snow parks compared to on-slope injuries. Accid. Anal. Prev. 2013, 50, 1221-1225. [CrossRef] [PubMed]

21. Ruedl, G.; Pocecco, E.; Sommersacher, R.; Gatterer, H.; Kopp, M.; Nachbauer, W.; Burtscher, M. Factors associated with self reported risk taking behaviour on ski slopes. Br. J. Sports Med. 2010, 44, $204-206$. [CrossRef] [PubMed]

22. Mittleman, M.A.; Maclure, M.; Tofler, G.H.; Sherwood, J.B.; Goldberg, R.J.; Muller, J.E. Triggering of acute myocardial infarction by heavy physical exertion-protection against triggering by regular exertion. N. Engl. J. Med. 1993, 329, 1677-1683. [CrossRef] [PubMed]

23. International Report on Snow and Mountain Tourism 2018. Available online: http://vanat.ch/RM-worldreport-2018.pdf (accessed on 28 October 2019).

24. Burtscher, M.; Federolf, P.; Nachbauer, W.; Kopp, M. Potential Health Benefits from Downhill Skiing: A Review. Front. Physiol. 2019, 9, 1924. [CrossRef] [PubMed]

(C) 2020 by the authors. Licensee MDPI, Basel, Switzerland. This article is an open access article distributed under the terms and conditions of the Creative Commons Attribution (CC BY) license (http://creativecommons.org/licenses/by/4.0/). 